\title{
Sparkling at the end of the tongue: The etiology of tip-of-the-tongue phenomenology
}

\author{
BENNETT L. SCHWARTZ \\ Florida International University, Miami, Florida
}

\begin{abstract}
The tip-of-the-tongue experience (TOT) is the phenomenological experience that a currently inaccessible word is stored in memory and will be retrieved. TOTs appear to be a universal experience that occurs frequently in everyday life, making the TOT an ideal case study in human phenomenology. This paper considers TOTs in light of Tulving's (1989) challenge to the doctrine of concordance, which is the assumption that behavior, cognition, and phenomenology are correlated, if not caused by identical processes. Psycholinguistic and memory theories, consistent with concordance, argue for direct access, or the view that TOTs and word retrieval are caused by the same retrieval processes. The metacognition view challenges concordance and views TOTs as an inference based on nontarget information that is accessible to rememberers. Current data, reviewed here, suggest that TOTs are caused via direct access and through inferential processes. Dissociations between TOTs and retrieval suggest that the causes of TOT phenomenology and the processes of retrieval are not identical.
\end{abstract}

Perhaps the most famous and most quoted passage from William James's (1890) Principles of Psychology is his description of the tip-of-the-tongue experience (TOT). In the quote, repeated in many cognitive psychology textbooks and many papers on the TOT, James writes,

The state of our consciousness is peculiar. There is a gap therein; but no mere gap. It is a gap that is intensely active. A sort of wraith of the name is in it, beckoning us in a given direction, making us at moments tingle with the sense of our closeness and then letting us sink back without the longed-for term. If wrong names are proposed to us, this singularly definite gap acts immediately so as to negate them. They do not fit the mould. And the gap of one word does not feel like the gap of another, all empty of content as both might seem necessarily to be when described as gaps. (p. 251)

James's description is particularly vivid and accords with most people's intuitive experience with TOTs. James's view is based solely on his astute but informal observations of human thought. The description is so insightful and complete that it presages modern research on the topic.

It was not until R. Brown and McNeill's 1966 paper on TOTs that empirical research on TOTs began. In a colorful description, Jones (1988) reported "Brown and McNeill showed in their justly famous article that the TOT state, hitherto a feral beast that struck without warning, could be tamed and studied as a creature of conveniently

The author thanks Alan Brown, Leslie Frazier, Janet Metcalfe, Walter Mischel, Thomas O. Nelson, Endel Tulving, John Wixted, and sev. eral anonymous reviewers for insightful commentary and discussion on preliminary versions of this manuscript. The author also thanks all of the informants who contributed to the language survey. Correspondence should be addressed to B. L. Schwartz, Department of Psychology, College of Arts and Sciences, Florida International University, Miami, FL 33199 (e-mail: schwartb@fiu.edu). regular habits" (p. 215). R. Brown and McNeill developed a methodology for inducing TOTs in a controlled setting. They provided students with definitions of difficult words (e.g., "A place where bees are raised for their honey") and asked the students to provide the word (apiary). In some instances, the students experienced TOTs; they were sure that they knew the word but were unable to retrieve it. R. Brown and McNeill were also curious about what the students could report about the missing target while they were experiencing a TOT. Therefore, they asked the students to report or guess the first letter of the missing target, the last letter of the missing target, the number of syllables, and any words that sounded similar or meant something similar. R. Brown and McNeill's basic methodology has been employed in almost all laboratory-based studies on TOTs ever since.

Another major landmark in the study of TOTs was an important review paper by A. S. Brown (1991), who summarized and organized the relevant research that had been done on TOTs during the 25-year period after R. Brown and McNeill (1966). His paper represents an exhaustive and thorough review of the work on TOTs up to 1991 (for another excellent review, see Smith, 1994). In almost every section of the review, A. S. Brown introduced critical theoretical questions about TOTs that warrant investigation, but most remain untested. The present paper does not intend to duplicate the coverage of A. S. Brown. Rather, the paper explores one area of importance: the etiology of TOT phenomenology.

The present paper is divided into several sections. First, I will outline Tulving's (1989) critique of the doctrine of concordance and how it applies to issues of TOT etiology. Then, I will outline a number of methodological distinctions in the empirical study of TOTs. I will show that many of the methodological differences arise from differences in assumptions related to the doctrine of concor- 
dance. In addition, I will make the case that TOTs are ideal case studies in human phenomenology because of their universality. In the second half of the paper, I will review the major theories of TOT etiology. I review the evidence for direct access and inferential approaches and how they account for the accuracy of TOTs in predicting recall, recognition, and knowledge of partial information. Finally, I conclude with a discussion of the role of TOTs in metacognition and suggest some directions for the future.

\section{THE DOCTRINE OF CONCORDANCE}

Tulving (1989) expressed dissatisfaction with what he called the doctrine of concordance. The doctrine of concordance is an implicit assumption in some contemporary cognitive research, unnamed until Tulving's critique. According to the doctrine, cognitive processes, behavior, and phenomenological experience are highly correlated. Indeed, Tulving argued that research in cognition has assumed that there is a "general, if not perfect, agreement between what people know, how they behave, and what they experience" (Tulving, 1989, p. 8). In this view, cognitive processes are the hidden mental computations that underlie our thought. Behavior is the observable action of a person. Phenomenological experience is the feeling that accompanies the cognitive processes and behavior. In general, Tulving claimed that some psychological research has assumed that behavior, cognition, and phenomenology should and will be closely connected. Tulving, however, challenged the doctrine by claiming that, in many cases, there may be dissociations between the underlying cognitive processes and the phenomenological experience that accompanies them.

In Tulving's view, cognitive psychology's concern with the mental computation, or cognitive processes, is not to be confused with the study of phenomenological experience. For example, the cognitive process of "retrieval" is not the same as the experience of "recollection" (Tulving, 1989). For successful recall to occur, the retrieval process combines a cue in the environment with an existing memory trace and elicits a particular response (see Tulving, 1983). The cognitive process of retrieval results in mental activity, which may lead to a behavior, such as articulating the target word. However, this retrieval process may not be accompanied by a feeling that recollection from memory has occurred. Words, for example, are retrieved from memory constantly during speech without experiencing recollection. Experienced recollection, or "mental time travel," occurs only in certain retrieval situations involving episodic memory. Mental time travel is the purely subjective experience that accompanies remembering that gives us the feeling of pastness. Moreover, other nonretrieval factors appear to affect our feelings of pastness (Jacoby, Kelley, \& Dywan, 1989). For these reasons, Tulving argued that the doctrine of concordance should no longer be accepted. Clearly, many of the issues in contemporary cognitive research (overcon- fidence, feelings of knowing, implicit memory, and false memory) suggest that many researchers no longer rely on concordance assumptions. Nonetheless, I will demonstrate that the assumption is still common in research on TOTs.

In the present paper, I make a logical extension of Tulving's critique of the doctrine of concordance. The assumption made here is that particular cognitive processes (or mental computation) are responsible both for observed behavior and for phenomenological experience. Under the doctrine of concordance, the likely scenario is that some cognitive processes produce both the observed behavior and the phenomenology. However, following Tulving's challenge, it is reasonable to postulate multiple cognitive processes, some that underlie behavior and others that underlie phenomenological experience. For example, if a particular cognitive process, such as retrieval, is not always accompanied by the same or any kind of phenomenological experience, it is likely that the phenomenological experience has a different underlying mechanism than the cognitive process itself. In some situations, such as implicit memory tests, retrieval is not accompanied by feelings of pastness. In other situations, of course, such as autobiographical memory tests, retrieval is accompanied by feelings of pastness. Indeed, feelings of pastness are possible without retrieval even taking place (e.g., memory illusions; see Roediger, 1996). Therefore, it is possible that some cognitive processes produce phenomenological experience, whereas other cognitive processes effect the actual behavioral response

Most TOT research implicitly endorses the doctrine. Contemporary research on TOTs has assumed that cognitive processes of retrieval and the phenomenology of TOTs are the same process. When exceptions to the doctrine are acknowledged, they have been considered to be unimportant (e.g., Astell \& Harley, 1996; Perfect \& Hanley, 1992; Rastle \& Burke, 1996). There are two major consequences of this assumption. First, researchers assume that variables that affect retrieval also affect TOTs. Therefore, they claim that one can infer the nature of retrieval by studying TOTs. This principle has guided most TOT research. Second, until now, most research studying TOTs has implied that phenomenology is redundant with retrieval because both tap the same underlying processes. Therefore, little research has been directed toward TOT phenomenology (but see Schwartz, Travis, Castro, $\&$ Smith, in press).

I claim that new TOT research refutes the doctrine of concordance by demonstrating that the processes of retrieval are not always identical to the processes that elicit TOTs. There is growing evidence to suggest that the etiology of TOTs differs from the processes that effect retrieval, leaving open the possibility for a breakdown in concordance. In the course of this paper, I present research from my own laboratory and from others suggesting that the TOT phenomenology is dissociable from the processes of word retrieval. 


\section{TOTS IN THE LABORATORY AND EVERYDAY LIFE}

The term TOT has been used in two different contexts, which I label first-person and third-person accounts of TOTs. The first-person, or introspectionist, approach views TOTs as the feeling of temporary inaccessibility, rather than the objective state of temporary inaccessibility (Smith, 1994). That is, TOTs are phenomenological experiences. People, when in a TOT, feel like they know the target word and will remember it eventually. The word, however, remains inaccessible. ${ }^{1}$ The first-person perspective is more consistent with Tulving's challenge to the doctrine of concordance because it emphasizes the phenomenology. The third-person perspective, by contrast, defines TOTs as instances of word-retrieval failures combined with partial accessibility (Kohn et al., 1987). That is, a TOT describes the contents of memory when a known word is not recalled; the feeling of knowing is not required. According to the third-person perspective, it may not even be necessary to ask the participant whether he or she is experiencing a TOT (e.g., Kohn et al., 1987; Vigliocco, Antonini, \& Garrett, 1997). Thus, third-person perspectives are consistent with the doctrine of concordance. To reiterate, in this paper, TOTs are considered to be first-person phenomenological experiences of rememberers. Gardiner and Java (1993) provided an excellent review concerning the differences between first- and thirdperson accounts of subjective aspects of remembering.

The "tip of the tongue" is a common-language expression that is used to describe the experience of the feeling of knowing that one can recall a word that, in fact, one cannot. The scientific terminology--TOT-is an attempt to capture and quantify that experience. First-person definitions given to rememberers in experiments have been generally consistent from research project to research project. Most research provides rememberers with a definition similar to the definition provided by R. Brown and McNeill (1966). They instructed their participants that "if you are unable to think the word but feel sure that you know it and that it is on the verge of coming back to you then you are in a TOT state" (p. 327). These two features of the TOT - inaccessibility and imminence - seem to be the key features of operational definitions of TOTs (A. S. Brown, 1991). For example, Rastle and Burke (1996) told participants that they were experiencing a TOT "if they were confident that they knew the word and it was on the verge of coming back to them" (p. 591). Schwartz and Smith (1997) defined the TOT as "a feeling that you can recall the answer. It is the feeling of being on the verge of being able to recall the answer that you cannot recall now" (p. 72).

TOTs have often been compared and equated to feelings of knowing. Although the two are closely related and are often highly correlated in empirical work (Schwartz, 1998 ), they are usually not defined in the same way. A. S. Brown (1991) defines feelings of knowing as assessments of recognition that may occur for all unrecalled items. Differences between low feeling of knowing and high feeling of knowing is a matter of degree. In contrast, TOTs "occur involuntarily" and are assessments that "subjects are confident that they can eventually recall the target information" (A. S. Brown, 1991, p. 205). TOTs and n-TOTs (unrecalled targets for which no TOT is reported) are qualitatively different states of mind. A. S. Brown's distinction is typical of the distinction that has been made by other researchers who have studied TOTs and feeling of knowing in the same experiment (e.g., Metcalfe, Schwartz, \& Joaquim, 1993; Schwartz, 1998; Yaniv \& Meyer, 1987).

\section{IS THE TOT UNIVERSAL?}

Although the TOT is used here and in the literature to denote the experience of temporary inaccessibility, in fact, the term tip of the tongue, as a technical psychological term, is borrowed from colloquial usage. Therefore, instructions to report TOTs are relatively easy to explain to participants and to be followed by participants. For comparison, elaborate instructions are necessary to elicit remember/know judgments (Gardiner \& Java, 1993; Rajaram, 1993; Rajaram \& Roediger, 1997). In the remember/ know paradigm, instructions and practice must be given to participants so that they can distinguish between the feeling of recollection expressed by the "remember" judgment and the feeling of knowledge expressed by the "know" judgment.

It is puzzling why people use the metaphor of the "tip of the tongue" to describe the experience of temporary inaccessibility. Does the expression capture the phenomenological experience, or is the expression just a peculiarity of the English language (and scientific usage)? If the expression captures the experience, one would expect other languages to use similar metaphors to describe the feeling. In order to answer this question, I conducted a survey. If terms exist in other languages to express temporary inaccessibility, but the terms do not use a "tongue" metaphor, then the phenomenology might vary as a function of language spoken. However, if most languages use the "tongue-based" metaphor to express temporary inaccessibility, then that supports the view that TOTs represent universal experience, common to all people. The last possibility bolsters the argument for using TOTs as a case study in human phenomenology.

I contacted fluent speakers, preferably native, of languages other than English. All of the people I spoke with were familiar with the English expression "on the tip of the tongue." I explained to them the definition of a TOT. I reminded them not to simply translate the literal English but rather to select the word or expression that described the experience that English speakers capture in the expression "on the tip of the tongue."

Across 51 languages known by my informants, 45 languages employed an expression that used the "tongue" metaphor to express the feeling of not being able to retrieve an accessible word (see Appendix A). American Sign Language (ASL), Icelandic, two sub-Saharan African languages (Kiswahili and Kalenjin), and Indonesian 
do not use the metaphor of the "tongue" to refer to the TOT. According to my informant, ASL does not have an expression literally meaning "on the tip of the finger." Five languages (Cantonese Chinese, Mandarin Chinese, Hindi, Hausa, and Ibo) use the related expression "in the mouth" to describe the experience. Japanese uses the expression "out of the throat" to describe temporary forgetting. Nonetheless, the overwhelming majority of languages use the "tongue" metaphor just as English does. Some languages also use multiple metaphors. For example, Korean uses both the "mouth" and the "tongue" metaphor, whereas French speakers use both the "tongue" metaphor and the expression "hole in my head" to express temporary forgetting. The survey suggests that the use of the "tongue" metaphor is not idiomatic to English but rather reflects a common aspect of TOT phenomenology.

The most common term was an almost literal equivalent of the English expression "on the tip of the tongue" (see Appendix B). For example, the expression in Italian is "sulla punta della lingua," and in Afrikaans, "op die punt van my tong," which both translate as "on the tip/point of the tongue." Other languages use slight variants. For example, Estonian ("keele otsa peal") translates to "at the head of the tongue," whereas Cheyenne ("navonotootse'a") translates as "I have lost it on my tongue." Irish ("ar flaen fy nhafod") refers to the "front of the tongue," whereas Welsh ("ar bharr theanga agam") translates to "on the top of my tongue." Marathi ("jeebhewar") simply uses "on the tongue." Perhaps the most poetic is Korean, in which the expression ("Hyeu kkedu-te mam-dol-da") means "sparkling at the end of my tongue."2 The general similarity of the expressions, however, does suggest that the "tongue" metaphor captures a common phenomenology across languages.

Study of TOTs gives us an empirical "lens" on the nature of phenomenological experience. Certain characteristics of TOTs make them useful to develop theories of phenomenology and experience. For example, TOTs appear to be common in everyday life, they are easy to induce in the lab, and they appear to be quite similar across language groups. Furthermore, although TOTs are phenomenological experiences, which only the rememberer is aware of, TOTs are linked to a specific objective behavior - namely, the attempts made to retrieve particular target words. Thus, the phenomenology can be directly compared to behavioral indices. Because of these features, TOTs offer us the opportunity to test theories concerning human phenomenology. In the following section, I address why most TOT studies have been more concerned about the state of knowledge during a TOT than in the TOT phenomenology itself.

\section{THE TOT IN DIFFERENT SUBDISCIPLINES}

Most research on TOTs has been guided by psycholinguistic, memory, or metacognitive approaches. Although these approaches can be grouped under a general rubric of cognitive psychology, the approaches differ in the assumptions made concerning the doctrine of concordance. It is my intention to alert researchers to the disagreements among them concerning their assumptions about concordance, so that discussion and debate can occur. My goal in this review, by pointing out differences, is to help synthesize disparate views, not to widen them.

\section{Psycholinguistics}

To date, probably the most research concerning TOTs has come from the psycholinguistic perspective, which focuses on TOTs as a temporary breakdown in lexical retrieval (see Burke, MacKay, Worthley, \& Wade, 1991). Research from this point of view has linked TOTs to other common errors in spoken language, such as slips of the tongue and spoonerisms (e.g., saying "toin coss" for "coin toss"). The psycholinguistic perspective tacitly assumes the doctrine of concordance. TOT phenomenology is interesting only to the extent that it tells us something about lexical retrieval. For this reason, many have made use of third-person TOTs as a "window" on word retrieval (Kohn et al., 1987; Vigliocco et al., 1997).

By studying what speakers know and can say when they are experiencing a TOT, psycholinguists can infer the multidimensional nature of words and the potential dissociation between a word's phonological, semantic, and lexical components. Rastle and Burke (1996), for example, wrote that "if there is sufficient semantic priming to activate the correct lexical node, but there is a deficit in phonological activation, a TOT response will be produced. Thus, TOTs provide a means of isolating phonological processes within a conceptually-driven task" (p. 594). Astell and Harley (1996) wrote that "the study of TOTs shed light on the processes of word selection and retrieval, both components of lexicalization in speech production" (p. 196). Meyer and Bock (1992) added that "the familiar tip-of-the-tongue (TOT) experience suggests that recovering a word from the mental.lexicon involves something more than a single, simple, look-up" (p. 715). Thus, the emphasis in this approach is what TOTs can tell us about lexical retrieval.

\section{Memory Perspectives}

The memory-oriented perspective to TOTs, like the psycholinguistic approach, assumes the doctrine of concordance. Researchers interested in memory have approached TOTs as a marker of retrieval processes gone awry. Indeed, A. S. Brown (1991) suggests that TOTs offer us an opportunity to study retrieval similar to "slowmotion photography." During a TOT, a known word cannot be recalled but is stored in memory. The memory approach has shared concerns with the psycholinguistic perspective-namely, an emphasis on the kinds of information that are accessible when a person is in a TOT and how TOTs are eventually resolved. Memory researchers emphasize, however, the process of retrieval and the nature of mnemonic cues. Smith (1994) wrote that "from a theoretical point of view, the TOT experience may be a 
key phenomenon for understanding memory retrieval (p. 28). Others are more concerned with what the TOT can tell us about the nature of temporary forgetting, such as Anderson and Neely (1996), who consider TOTs to indicate interference in memory. They write that "the clearest examples of this experience [interference] occur during tip-of-the-tongue states, in which our ability to name a particular person, place, or object seems thwarted by a persistently intrusive word" (p. 248). Thus, like the psycholinguistic view, the memory view also implicitly endorses the doctrine of concordance because of its equation of TOTs with the retrieval process.

\section{Metacognitive Approach}

Metacognitive models emphasize the role that monitoring and controlling processes play in cognition (e.g., Bjork, 1994; Metcalfe, 1993; Nelson, 1996; Nelson \& Narens, 1990, 1994). In these models, metacognitive processes are separate from the cognition that they monitor and control. Typically, one process, considered the object-level process, carries out the behavior, whether it is learning, remembering, or problem solving. The second, or meta-level process, monitors the object-level process, often with the goal of effectively controlling the objectlevel process (see, e.g., Nelson \& Narens, 1990). Metacognitive models, therefore, do not assume the doctrine of concordance because it is possible that phenomenology is a function of the metacognitive process rather than the ongoing cognitive processes. Although Nelson and Narens's model does not specifically discuss TOTs, the current adaptation of the model suggests that TOTs are phenomenological consequences of a monitoring process that indicates that an unrecalled word may be known. The monitoring process that elicits TOTs is separable from the cognitive process that effects retrieval.

The metacognitive model lends itself to the study of the phenomenology of TOTs. Smith (1994) wrote that "in the course of recalling names or words, people sometimes find themselves in a 'tip-of-the-tongue' state, a discomfiting experience in which a seemingly well-known term appears to be blocked from conscious awareness" (p. 27). Note, in this quote, that the emphasis is on the feel of the TOT. In fact, Schwartz et al. (in press) found that TOTs could be divided into substates, depending on their phenomenological status. They found that rememberers could distinguish between strong and weak TOTs, emotional and nonemotional TOTs, and imminent and nonimminent TOTs.

Another aspect of TOTs that is emphasized in the metacognitive model is why TOTs are accurate predictors of performance. Because the process of retrieval and the process that produces TOTs are thought to be different, the reason why they are so highly correlated becomes an important question. Therefore, consideration of how and when TOTs are predictive of future performance is important because the monitoring that produces the TOTs may not always be accurate.

\section{Other Approaches}

Three other approaches are grouped together because research within these traditions is sparse and mostly draws on either the psycholinguistic model or the memory model. I included them here for completeness. However, throughout the rest of this article, I will only refer to this work inasmuch as the papers reviewed here overlap with the psycholinguistic, memory, or metacognitive perspectives.

The everyday-ecological approach (e.g., Read \& Bruce, 1982; Reason \& Lucas, 1984) has considered TOTs to be an important topic because TOTs are "inherently interesting" to both researchers and laypeople (A. S. Brown, 1991). Everyday approaches have often stressed "diary" studies in which people record naturally occurring TOTs in their daily lives (Burke et al., 1991; Reason \& Lucas, 1984). Retrospective questionnaires are also used in this approach (Burke et al., 1991). These studies reveal that TOTs are common experiences; most people experience one at least once during any given week (Burke et al., 1991). Moreover, most people usually report being able to resolve them (i.e., eventually recall the missing target) if given enough time.

Developmental approaches have examined TOTs in children and in older adults. Two studies have looked at TOTs in young children (Elbers, 1985; Wellman, 1977). Cognitive gerontology has maintained an interest in TOTs because across many studies, it has been demonstrated that older people experience more TOTs than younger people (A. S. Brown \& Nix, 1996; Burke et al., 1991; Finley \& Sharp, 1989; Maylor, 1990; Rastle \& Burke, 1996). Neuropsychological approaches have looked at TOTs in patient populations, such as patients with Alzheimer's disease (Astell \& Harley, 1996), patients with Parkinson's disease (Matison, Mayeux, Rosen, \& Fahn, 1982), and aphasics (Bruce \& Howard, 1988; Funnell, Metcalfe, \& Tsapkani, 1996; Vigliocco, Vinson, Martin, \& Garrett, 1999). This area holds considerable promise, but the research remains inchoate.

To summarize, most research on TOTs has assumed the doctrine of concordance. The exception is research motivated by metacognitive models. Metacognitive models assume that TOTs are the output of a monitoring system separable from the retrieval process. Therefore, the metacognitive model leads to greater attention to the relation between TOTs and retrieval (e.g., accuracy) and to the phenomenology of the TOT itself.

\section{THEORIES OF TOT}

In this section, the major contemporary cognitive theories concerning the etiology of TOTs will be considered. Each theory will be discussed with regard to the data that support it and its relation to the doctrine of concordance. Nelson, Gerler, and Narens (1984) categorized theories concerning the bases of metamemory into two main classes (for a more recent review, see Schwartz, 1994). Recently, these classes have been applied to TOTs 
(Metcalfe et al., 1993; Schwartz \& Smith, 1997; Smith, 1994). The two classes of theories were labeled directaccess views and inferential views. Direct-access views argue that TOTs arise from sensitivity to the unretrieved target. Although items have insufficient memory "strength" to be recalled, they are strong enough to signal TOTs. Inferential views claim that TOTs are not based directly on an inaccessible but activated target. Rather, TOTs arise from clues that the rememberer can piece together. These clues are information that is accessible to the rememberer, such as information from the retrieval cue or information related to the target that is retrieved. Although direct-access and inferential views are not mutually exclusive, they represent very different approaches to the etiology of TOTs, and have led to different research emphases. The two classes of theories differ with respect to their position on the doctrine of concordance. Direct-access views typically implicitly endorse concordance, whereas inferential views usually challenge the doctrine.

\section{Direct-Access Views}

Direct-access approaches fall into three basic views. The first view, the blocking hypothesis (i.e., Jones, 1989), contends that TOTs occur when a retrieval cue prompts retrieval of an incorrect but closely related word. The realization that the retrieved word is incorrect prompts the experience of the TOT. The second view, the incomplete activation hypothesis, states that the TOT occurs when rememberers cannot recall the target word but sense its presence nonetheless. The third direct-access view has been developed by Burke and her colleagues (Burke et al., 1991; Rastle \& Burke, 1996; see also Harley \& Bown, 1998). Burke's view, the transmission deficit model, argues that TOTs arise from a multicomponent memory representation. TOTs occur when there is activation of the semantic component of the word, but priming does not pass to the phonological level of the word. For example, on hearing the definition, "a device for protection from the rain or sun," a semantic and perhaps a visual representation of the object may be retrieved, but the definition does not activate the phonological representation (e.g., the word umbrella).

\section{Support for the Direct-Access View}

Support for the view that TOTs are a product arising from the same processes that support retrieval will be reviewed in this section. Three basic kinds of evidence have been used to support direct access: resolution and recognition of TOT targets, and retrieval of partial information. Each methodology reveals strong associations between TOTs and retrieval. The evidence reviewed here supports each of the three different direct-access views.

Resolution of TOT targets. Support for the assumption that TOTs arise from retrieval processes comes from studies that find strong positive correlations between the likelihood of experiencing a TOT and the likelihood of resolving the target. Resolution is the uncued retrieval of a previously unrecalled TOT item. In one diary study, $96 \%$ of recorded TOTs were reported as eventually resolved
(Burke et al., 1991). This remarkably high percentage seems to indicate a high correspondence between TOT phenomenology and objective performance. However, Burke et al. included "consulting a person or book" (p. 553) as successful resolution, and this may inflate resolution rates. Furthermore, participants may be more inclined to report resolved TOTs than unresolved TOTs. Another problem with diary studies is that resolution rates cannot be determined for $n$-TOTs (unrecalled items that are not accompanied by TOTs). Thus, one cannot compare resolution rates for unrecalled words that are not accompanied by TOTs. Thus, laboratory studies may provide a better index of the accuracy of TOTs at predicting resolution.

In the laboratory, resolution rates with definitions or general-information questions are typically around $40 \%$ (A. S. Brown, 1991). Resolution is even lower with episodic-memory stimuli (Ryan, Petty, \& Wenzlaff, 1982; Schwartz, 1998). Typically, however, laboratory data are based on studies that investigate immediate resolution, whereas diary studies tap both immediate and delayed resolution. Indeed, Smith (1994) found that immediate resolution of TOTs for fictional animals was $9 \%$. Resolution rose to $43 \%$ after a 6 -min delay. Furthermore, Smith found that resolution was much more likely to occur after a TOT than after an n-TOT (an item not recalled that does not produce a TOT). Resolution rates for n-TOTs were $3 \%$ at the immediate test and $19 \%$ at the delayed test. Schwartz (1998) also found lower resolution rates for n-TOTs. These studies demonstrate a strong correspondence between TOTs and the likelihood of successful resolutions, which supports the view that TOTs reflect target retrieval processes.

Recognition of TOT targets. Although an item may not be strong enough to be recalled, it may exist in memory and may be accurately recognized. For this reason, a recognition test can assess whether the TOT items are actually of higher activation than items not in a TOT. Some TOT studies have looked at recognition of targets after the rememberers experienced TOTs and when they did not (e.g., Burke et al., 1991; Kozlowski, 1977; Schwartz, 1998; Schwartz \& Smith, 1997; Schwartz et al., in press; Smith, Balfour, \& J. M. Brown, 1994; Widner, Smith, \& Graziano, 1996). Recognition of the correct target following a TOT is far greater than recognition of the correct target when rememberers are not experiencing a TOT (see Table 1). Schwartz (1998) measured the gamma correlation between TOTs and recognition, finding a correlation of .66 between TOTs and correct recognition (see Nelson, 1984, for discussion of the gamma correlation). Thus, like resolution, studies that examine recognition also find strong correlations between the presence of TOTs and the likelihood of correct target retrieval.

Partial information of TOT targets. A. S. Brown (1991) provided a thorough review of this literature that I will not attempt to duplicate but will briefly summarize and update. In partial information reports, the rememberers are asked to recall specific aspects of the target word. Usually, this involves phonological information, 
Table 1

Percent Correct on Recognition Tests as a Function of Phenomenological State, TOT and n-TOT (Items Not Recalled and Not in TOT)

\begin{tabular}{ccc} 
Study & TOT & n-TOT \\
\hline Burke et al. (1991) & 81 & not reported \\
Kozlowski (1977) & 73 & 46 \\
Schwartz (1998) & & \\
Experiment 1 & 81 & 63 \\
Experiment 2 & 40 & 11 \\
Schwartz \& Smith (1997) & & \\
Experiment 1 & 81 & 70 \\
Experiment 2 & 83 & 74 \\
Experiment 3 & 84 & 64 \\
Schwartz et al. (in press) & & \\
Experiment 1 & 33 & 10 \\
Experiment 2 & 35 & 10 \\
Experiment 3 & 32 & 10 \\
Smith et al. (1994) & 78 & 57
\end{tabular}

Note-Higher recognition performance for TOTs than for n-TOTs indicates accurate performance.

such as the first letter, the number of syllables, and the syllabic stress (R. Brown \& McNeill, 1966; Rubin, 1975). Participants may also be asked whether they can retrieve words that sound similar to or mean something similar to the TOT target. The rationale for this kind of report is the assumption that the TOT reflects activation of a target word but insufficient activation to achieve recall. Yet there may be enough activation to allow for partial recall. Indeed, almost all studies that elicit partial information find that participants can accurately retrieve some partial information. TOTs have been shown to be correlated with knowledge of first letters, last letters, number of syllables, knowledge of similar words, and syllabic stress (see A. S. Brown, 1991). Koriat and Lieblich (1974) showed that more partial information was retrieved when rememberers were in TOTs than could be explained by a normative guessing strategy. This is not limited to English. Murakami (1980) found partial recall of letters in Japanese, and Bak (1987) found partial recall of first letters in Polish. Bak also documented that Polish rememberers were able to retrieve words that sounded similar to or meant something similar to the TOT word.

More recent studies have examined the relation between TOTs and syntactical features of language. Italian-speaking rememberers have access to the gender of words when in a TOT (Miozzo \& Caramazza, 1997; Vigliocco et al., 1997). Iwasaki, Vigliocco, and Garrett (in press) found that Japanese rememberers had access to parts of speech, such as whether a word was an adjective or an adjectival noun, when in a TOT. Furthermore, Vigliocco et al. (1999) found that English-speaking participants have access to the type of article used for "mass" (i.e., some) or "count" (i.e., the) nouns when in a TOT. For example, the words water and asparagus are never pluralized; we indicate quantity by terms such as more, some, and less. These are considered mass nouns. Count nouns, such as cucumber and photograph, are pluralized by adding an $s$. In the absence of being able to recall the target word, rememberers are nonetheless able to categorize them as mass or count better than chance when in a TOT.

TOTs have been shown to be accurate predictors of objective memory performance. Moreover, when rememberers are experiencing TOTs, they often successfully recall partial information about the target. This suggests that people experiencing TOTs are retrieving target information. Therefore, these phenomena are consistent with the position that the retrieval process is causing the TOT for the unrecalled word. Thus, these findings support the view that TOTs reflect target word activation. Moreover, because of the strong correlation between TOTs and aspects of target retrieval, they offer support for the doctrine of concordance as well.

To summarize, a large database exists demonstrating a strong correlation between TOTs and the likelihood of resolution, recognition, and retrieval of partial information. This strong correlation is suggestive, but not conclusive, of direct-access mechanisms. Indeed, inferential mechanisms can also account for these correlations (i.e., Koriat, 1993). Nonetheless, I have included them in this section because of general acceptance that the accessibility of partial information and the eventual retrieval of TOTs support direct-access mechanism (i.e., A. S. Brown, 1991; Vigliocco et al., 1997).

Direct-access approaches divide into three separate views: the blocking hypothesis, the incomplete activation hypothesis, and the two-stage transmission deficit model (Burke et al., 1991). Although all three hypotheses agree that TOTs arise from access to an unretrieved target, each postulates a different mechanism. I now examine each of these three specific theories in greater detail.

\section{Blocking Hypothesis}

The blocking hypothesis states that TOTs occur because rememberers retrieve target words related to the correct target but are recognized by the rememberers as being incorrect (Jones, 1989). According to the blocking hypothesis, TOTs occur because the rememberers recognize blockers as incorrect but cannot retrieve the correct but inhibited target. A. S. Brown (1991) wrote, "the blocking perspective suggests that the TOT represents a memory search that has become sidetracked" (p. 215). The incorrect intruders that sidetrack retrieval have been labeled as blockers (Reason \& Lucas, 1984), interlopers (Jones, 1989; Jones \& Langford, 1987), and related words (A. S. Brown, 1991). The hypothesis suggests that variables that increase the retrieval of these blockers will both inhibit correct recall and promote TOTs.

Like other direct-access models, the blocking hypothesis easily accounts for why TOTs accurately predict memory performance. Accuracy is ensured because TOTs are caused by activation of target memories. Because TOTs are caused by activation of the sought-for word, a change in retrieval conditions may remove the processes that are inhibiting retrieval. Retrieval may be inhibited by blockers, but the blockers are recognized as incorrect. Once the inhibition is removed by a change in retrieval cues or the forgetting of the blocker, TOTs will be resolved. 
Evidence concerning blocking. The blocking hypothesis suggests that the rememberers retrieve words or blockers that are recognized as incorrect but that interfere with correct retrieval. Empirically, however, this is difficult to measure. In fact, most of the research directed at blocking has provided words or blockers thought to be capable of providing interference and has examined whether these words induce TOTs.

Jones and his colleagues (Jones, 1989; Jones \& Langford, 1987) used experimenter-provided blockers to examine the blocking hypothesis. Participants were presented with the definitions of difficult words and were asked to retrieve a target word. For some of the items (banal), Jones presented a word that was semantically related (uninspired) to the target word along with the definition. For other items (bibliophile), Jones presented a word that was phonologically related (buffoonery). If blocking is crucial to TOTs, then presenting a potential blocker should increase the likelihood that the participants report a TOT. In fact, semantic blockers did not increase the likelihood of a TOT, but phonological blockers did. Jones, however, did not counterbalance the target words from the semantic, phonological, and control condition, and the results were actually a function of the particular words that were in each condition (see Meyer \& Bock, 1992; Perfect \& Hanley, 1992). When materials were counterbalanced, Meyer and Bock (1992) found that the condition that led to the highest reported TOT levels, the phonological cuing condition, actually led to the highest number of correct responses, but there were no differences in number of reported TOTs. Moreover, Perfect and Hanley (1992) included a control condition in which the same stimuli that Jones used were shown without the presence of the blocking words. Perfect and Hanley found that the words that Jones (1989) had used in the phonological blocking condition resulted in more TOTs even when no blocking words were included. Perfect and Hanley, like Meyer and Bock, argued against any role for blocking in the etiology of TOTs.

Smith (1994) did find evidence that supports the blocking view using episodic-memory stimuli. Rememberers learned the names of fictional animals. Later, at test, they were presented with the picture of the animal, along with a word that was phonologically similar to the name, the name of another animal, or a word that was unrelated to the target name. Smith found that the phonologically similar items increased recall, relative to the control, without increasing the reported number of TOTs. The semantically similar cues increased both recall and TOTs. This pattern of results is consistent with the blocking hypothesis. Semantically similar items caused participants to think the items were recallable. It is not clear, however, whether the TOTs resulted from blocking of target retrieval with misleading information or the TOTs were induced because semantically similar items serve as subjectively better cues (see Cue Familiarity section below).

Blocking theory states that the rememberers retrieve blockers, and these interfere with retrieval of the correct target. The blocking hypothesis is difficult to evalu- ate experimentally because it is not clear whether the experimenter-provided blockers serve as blocker or retrieval cues. Furthermore, it is also unclear whether the experimenter-provided blockers actually mimic the role of blocking in retrieval and TOT etiology. Therefore, despite the mixed evidence on blocking, it should remain a viable hypothesis. Indeed, it is a hypothesis waiting for a better, as yet undiscovered, methodology.

\section{Incomplete Activation}

The incomplete activation theory states that TOTs are caused by sensitivity to the existence of an unrecalled target in memory, accompanied by the failure to retrieve the target into conscious memory. In an incomplete activation model (R. Brown \& McNeill, 1966), TOTs occur because a target word is strong enough to induce a TOT but not strong enough to elicit recall. Incomplete activation invokes a direct-access mechanism to account for TOTs, which are simply intermediate states of knowledge.

In incomplete activation, the accuracy with which TOTs predict memory performance is straightforward. TOTs should occur only for target words that are present in memory because TOTs represent intermediate memory strengths. Because accessibility may fluctuate due to transitory factors, an item that is currently inaccessible, but in a TOT, may fluctuate to higher accessibility or strength and then be resolved. Because TOTs represent higher activation than unrecalled items not in a TOT, TOT targets will be more likely to be recognized. Incomplete activation theory is also consistent with the doctrine of concordance, since the phenomenology of TOTs arises from the strength of a memory trace.

\section{Transmission Deficit Model}

In the transmission deficit model (Burke et al., 1991; Rastle \& Burke, 1996), TOTs are induced whenever the semantic representation of a word is activated, but the activation fails to prime the complete phonological representation of the target word (see Figure 1). The transmission deficit model differs from the incomplete activation model because it assumes two separate target representations: semantic and phonological. For this reason, Harley and Bown (1998) label the transmission deficit model a two-stage model of TOTs and label the incomplete activation model a one-stage model.

Burke et al. (1991) wrote that the "basic cause of TOTs in the NST [transmission deficit model] is a deficit in the transmission of priming across critical connections required for producing the target word" (p. 545). Therefore, although the model requires a dual representation of the target, TOTs arise from direct access to these particular representations and via the same process that is used in retrieval. Because a single process elicits both retrieval and the TOT phenomenology, the transmission deficit model implicitly endorses the doctrine of concordance.

The explanation for the accuracy with which TOTs predict later memory performance is similar to the account of accuracy discussed in the Incomplete Activation section. When a word definition is given, the semantic rep- 
SEMANTIC

SYSTEM

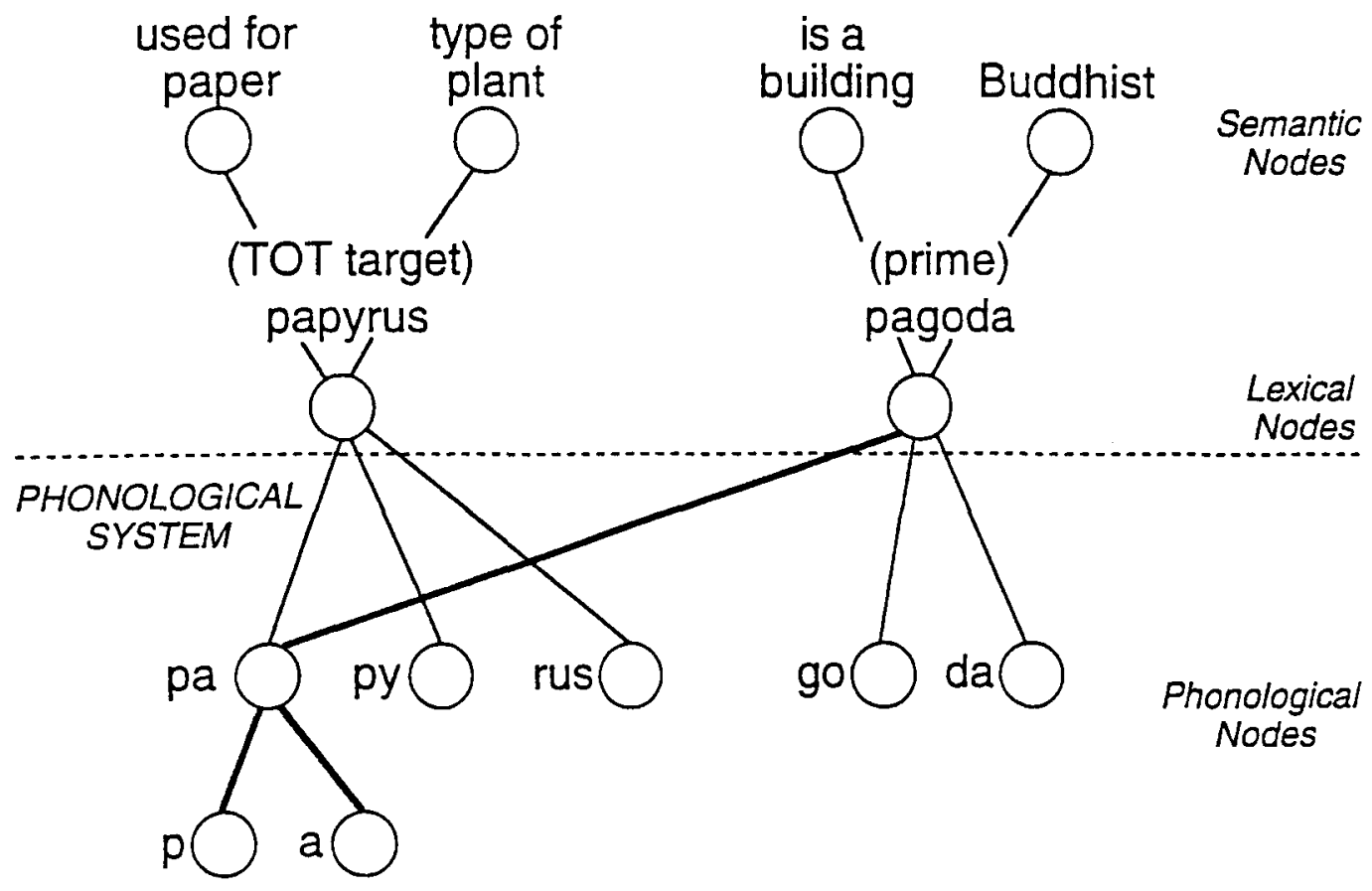

Figure 1. Burke et al.'s transmission deficit model. From "On the Tip of the Tongue: What causes word finding failures in young and older adults?" by D. M. Burke, D. G. MacKay, J. S. Worthley, and E. Wade, 1991, Journal of Memory and Language, 30, p. 544. Copyright 1991 by Academic Press. Reprinted with permission.

resentation of the target word is activated. Priming spreads to an existing phonological representation. Changes in retrieval conditions will lead to changes in activation and priming, which may result in resolution of TOTs.

The model makes some specific predictions concerning the likelihood of TOTs. First, connections between the semantic and phonological levels become stronger with greater use. Therefore, less frequently used words (e.g., kiosk, sump) should give rise to more TOTs than common words (e.g., house, girl). Second, recency of use strengthens connections. Words that have not been encountered recently should be more likely to induce TOTs than less recently encountered words. Third, aging also weakens connections between the semantic and phonological levels. Therefore, older people should experience more TOTs than younger people. In a series of studies, including both diary studies and experimental techniques, Burke et al. (1991) found support for all three of these hypotheses. Rastle and Burke (1996) examined the effect of semantic and phonological priming of the target on the likelihood of TOTs in a general-information paradigm. They found that phonological priming increased the number of correct responses and decreased the number of TOTs. Semantic priming had no additional effects. Rastle and Burke argue that the lowering of TOT rates via phonological priming supports the transmission def- icit model because the priming increases the level of phonological activation, which then makes the target word more accessible.

Harley and Bown (1998) have also found results that are consistent with a two-stage model of TOTs, similar to Burke et al.'s (1991) transmission deficit model. Harley and Bown varied the frequency of words and the number of lexical neighbors (i.e., closely related phonological words). They found that TOTs were more likely for lowfrequency words than for high-frequency words and that TOTs were more likely for those items with fewer close phonological neighbors. Both effects are consistent with a view that TOTs are the result of a breakdown between phonological and semantic representations.

One methodological problem clouds the interpretation of data from Rastle and Burke (1996) and Harley and Bown (1998). In both studies, the interest was in the effect of manipulated experimental variables on both recall and the number of TOTs. Because TOTs can only be made on those items not originally recalled, measured recall and TOTs are not independent of each other. If there are differences in recall, the subset of items for which TOTs can be given may be different. If an experimental variable, such as the phonological priming variable in the Rastle and Burke experiments, increases recall, then it decreases the set of items on which TOT 
judgments can be made. Thus, in the Rastle and Burke study, it is possible that the unrecalled words in the phonological primed condition represented a harder set of items than the unrecalled unprimed words. Thus, the lower rate of TOTs may be a function of the more difficult items and not the manipulated variable (see Schwartz \& Metcalfe, 1994). When evaluating etiologic issues in TOTs, it important to equate recall or recognition across experimental conditions.

The transmission deficit model can account for much of the data on TOTs. It succinctly accounts for frequency effects, neighborhood effects, phonological priming, the accessibility of partial information, and differences in TOTs between younger and older rememberers. However, it cannot explain some of the data, such as cue priming, which provide support for inferential theories and challenge the doctrine of concordance. Therefore, it is likely that any adequate explanation of TOTs will need to include a mechanism similar to the transmission deficit model or another direct-access mechanism with a mechanism that produces TOTs inferentially.

\section{Inferential Views}

In the inferential approach, the TOTs are not based on sensitivity to inaccessible but activated targets. Instead, rememberers infer the target's existence from clues that inform us that it is likely to be in memory. The clues that are used to make the inference may include the cue (e.g., Metcalfe et al., 1993), retrieved partial information about the target (Koriat, 1993), or any generated information related to the target name (Schwartz \& Smith, 1997). Cues can be considered anything in the environment that may help the rememberers retrieve the sought-for target. Generated information may consist of bits and fragments of the sought-for target or may consist of words, pictures, and other kinds of information that are related to the target. Inferential approaches to metacognition have been shown to be useful in explaining the bases of several different metacognitive judgments, including speeded feeling of knowing (Reder, 1987; Reder \& Ritter, 1992), slower feeling-of-knowing judgments (Koriat, 1993; Metcalfe, 1993; Metcalfe et al., 1993; Schwartz, 1994; Schwartz \& Metcalfe, 1992), and judgments of learning (Benjamin, Bjork, \& Schwartz, 1998; Koriat, 1997). Inferential explanations, developed within a metacognitive perspective, are inconsistent with the doctrine of concordance. The inferential approach assumes that TOTs are caused by a process other than the retrieval process. Therefore, consistent with Tulving (1989), the phenomenology of TOTs is elicited by one process, and target retrieval occurs by another.

Unlike the straightforward manner in which directaccess views account for the accuracy with which TOTs predict recognition, the inferential account of accuracy requires an additional step. The inferential view claims that the processes that produce TOTs and the processes that effect target retrieval are generally correlated. Thus, when cues are familiar and considerable related information is retrieved, the rememberers will usually have a representation of the target word in memory. Unfamiliar cues that do not elicit related information are, correspondingly, less likely to induce TOTs, but it is also likely that the rememberers will not have the target representation. In this way, TOTs are thought to be a product of a heuristic. The experience of a TOT generally means that target retrieval is likely; however, because the TOT is not based on target retrieval, occasions will arise when a TOT is elicited by certain factors when no representation of the target is present. Thus, inferential mechanisms can also account for the high correlation between resolution, recognition, and access to partial information, if we assume that the processes that cause TOTs are correlated to the processes that evoke retrieval.

There are two main hypotheses within the inferential framework. Like the difference between direct access and inferential in general, these two hypotheses are not mutually exclusive. Cue familiarity theory suggests that some TOTs arise because of a strong feeling elicited by recognizing a familiar cue (Metcalfe et al., 1993). Koriat's $(1993,1995)$ accessibility heuristic argues that TOTs may arise from inferences made on the basis of the amount and kind of information retrieved from memory when the target is not recalled. In the next two sections, I consider the evidence for each of these views.

\section{Cue Familiarity}

The cue familiarity hypothesis states that TOTs are based on an assessment of the level of recognition of a particular cue or question (Metcalfe et al., 1993). This approach dismisses the relevance of the unretrieved target altogether and instead emphasizes the role of the cue. In its purest form, the cue familiarity hypothesis suggests that a familiar cue should induce a TOT regardless of whether or not the target is known. There is a large database describing the importance of cue familiarity in feeling-of-knowing judgments (Connor, Balota, \& Neely, 1992; Metcalfe, 1993; Metcalfe et al., 1993; Reder, 1987; Reder \& Ritter, 1992; Schwartz \& Metcalfe, 1992). However, less data exist linking cue familiarity with TOTs.

Koriat and Lieblich (1977) examined the relation between TOTs and the cues or questions that elicited the TOTs. They labeled the questions as pointers because they "point" or cue the relevant target answer. Koriat and Lieblich analyzed the pointers along several dimensions, but the most relevant finding is that question redundancy led to more TOTs for unrecalled items than more succinct definitions. For example, definitions with repetitive elements, such as "a circle, or any indication of radiant light, around the heads of divinities, saints, sovereigns in pictures, medal, etc." (nimbus) tended to produce more TOTs than did more concise definitions, such as "the science of coins" (numismatics). This trend toward more TOTs in questions with repetitive elements in the cue was the same across TOTs that were resolved (i.e., even- 
tually recalled or recognized) and those that were not. Thus, Koriat and Lieblich's results suggest that cue factors play a role in causing TOTs.

Metcalfe et al. (1993) directly tested the roles of cuebased sources in TOTs in an episodic-memory paradigm. Participants studied cue-target word pairs. In one condition, both the cue and the target were repeated $(\mathrm{A}-\mathrm{B}$ A-B). In a second condition, the cue was repeated, but with a new unrelated target (A-B A-D). In a third condition, neither the cue nor the target was repeated (A-B $C-D)$. In accordance with results from interference paradigms, Metcalfe et al. found that the A-B A-D condition showed the lowest recall. Recall was highest in the $\mathrm{A}-\mathrm{B}$ $\mathrm{A}-\mathrm{B}$ condition, presumably because both cue and target are repeated. If TOTs are based on the strength of the representation, as predicted by incomplete activation, the $\mathrm{A}-\mathrm{B} \mathrm{A}-\mathrm{B}$ condition should show the highest number of TOTs ${ }^{3}$ Cue familiarity, however, predicts that because the cue is repeated in both conditions ( $A-B A-B$ and A-B A-D), TOTs will be high for each when compared with the condition in which the cue is presented only once (A-B C-D). Indeed, Metcalfe et al. found that the repetition condition ( $\mathrm{A}-\mathrm{B} \mathrm{A}-\mathrm{B})$ and the interference condition (A-B A-D) both showed a high percentage of TOTs relative to the once-presented condition. Thus, they found that cue repetition led to more TOTs, regardless of the level of memorability.

\section{Accessibility Heuristic}

Koriat $(1993,1995)$ argued that feeling-of-knowing judgments are based on the amount and intensity of partial information that rememberers retrieve when they cannot recall a target answer. Koriat's view is inferential because the judgment is only made on accessible information, and it is not based on inaccessible but available targets. Schwartz and Smith (1997) hypothesized a similar basis for TOTs, arguing that the amount and intensity of retrieved information may also play a role in the etiology of TOTs. TOTs are caused by information that is retrieved, but that information may be actually tangential to the sought-for target.

To test this hypothesis, Schwartz and Smith (1997) presented participants with lists of nonsense words. Each word was paired with the name of a country, and some of the words were also accompanied by line drawings of fictional animals. Participants were told that each nonsense word was the name of an animal, and the country name was the habitat of that animal. For example, participants might have seen Yelkey-Panama, which indicated that the "yelkey" is an animal that lives in Panama. Of the animals for which line drawings were provided, half were also accompanied by information pertaining to the size and diet of the animal. The three encoding conditions were minimum-information (just the name-country pair), medium information (the name-country pair and line drawing), and maximum inforination (the namecountry pair, line drawing, and diet and habitat information). The conditions were designed to allow different amounts of information to be retrieved when the partic- ipants were given the country name as a cue for the retrieval of the animal name. If the participants could not retrieve the name of the animal associated to a given country cue, they were then asked for a TOT judgment and asked to guess at the first letter of the animal's name. The participants were also asked to retrieve as much related information as they could. Related information included both biographical information and descriptions of the appearance of the animal.

The encoding manipulation did not affect recall of animal names, nor did it affect the recognition of unrecalled names. Thus, the set of items on which TOTs were to be made was equated. However, consistent with Koriat's $(1993,1995)$ accessibility theory, there were more TOTs reported in the medium and maximum information conditions $(19 \%)$ than in the minimum information condition (11\%). Moreover, the number of reported TOTs was correlated with the amount of related information retrieved. Thus, when more information was accessible to participants, they were more likely to experience TOTs.

The accessibility framework offered by Koriat offers an alternative explanation for the findings linking the retrieval of partial information with the likelihood of a TOT (i.e., R. Brown \& McNeill, 1966; Koriat \& Lieblich, 1974; Rubin, 1975; Vigliocco et al., 1997; Vigliocco et al., 1999). If partial related information is retrieved, it may be the presence of that information itself, regardless of whether or not the representation is activated, that induces the TOT. Therefore, much of the data that support the direct-access view can also support the accessibility view. Indeed, blocking effects on TOTs are also amenable to the accessibility view. However, only one published study directly supports the role of the retrieval of related information in the formation of TOTs (Schwartz \& Smith, 1997). Therefore, the hypothesis should be considered tentative at best. Nonetheless, the research accumulating on inferential views of TOTs suggests that, in some circumstances, TOTs are based on clues of memorability rather than memorability itself.

\section{The Heuristic Account of Accuracy}

Inferential views, compared with direct-access theories, require a more complicated explanation of why TOTs are accurate predictors of performance. For inferential views, the actual presence of the target is not a given, and, therefore, accuracy must rely on the natural correlation between the factors that rememberers use to infer TOTs and the factors that actually influence temporary forgetting and subsequent retrieval. Accessibility theory, which centers on the evaluation of partial information, accounts for accuracy by suggesting that people tend to retrieve more correct than incorrect information (Koriat, 1993). If more correct than incorrect information is retrieved, TOTs will tend to be accurate in predicting eventual resolution or recall. The TOT experience may indicate-correctly most of the time - that retrieval is indeed imminent.

The TOT has been referred to as a cognitive heuristic (e.g., Schwartz, 1998; Smith, 1994). The heuristic account cogently explains why some TOTs are not resolved 
or recognized. These TOTs may be spurious experiences caused by familiar cues or the retrieval of related information. Indeed, in the case of illusory TOTs, the person cannot know the target answer (Schwartz, 1998). Thus, cases of "negative" TOTs (Vigliocco et al., 1997), TOTs for incorrect items (Rastle \& Burke, 1996), and illusory TOTs (Schwartz, 1998) may be best thought of as errors produced by inferential heuristics. Heuristics can therefore account for both the general accuracy of TOTs and the existence of unresolved, unrecognized, or illusory TOTs.

The heuristic approach to TOTs is also consistent with Tulving's view on the doctrine of concordance. TOTs are accurate at predicting memory performance because they arise from processes correlated with retrieval but not directly from retrieval itself. This correlation does not imply that the cognitive processes are identical, but only that they are linked. In fact, the linkage may occur only because of features of the external environment. Concordance does not preclude significant correlations between cognitive processes and phenomenology. Rather, it suggests that the processes may be separable, as indeed they appear to be with some TOTs.

\section{TOTs AS METACOGNITION}

The TOT phenomenon has been presented from three different perspectives: the psycholinguistic approach, which views TOTs as a "window" on word retrieval; the memory perspective, which views TOTs as markers of available, but inaccessible, target memories; and the metacognitive perspective, which views TOTs as a phenomenological experience about memory retrieval. Metacognition, by definition, is concerned with cognitions about cognitions and thereby is necessarily related to the study of consciousness (see Nelson, 1996). Because firstperson TOTs are experiences whose referent is a cognitive process (retrieval), TOTs are indeed classifiable as metacognitive judgments. Nelson (1996) distinguishes be- tween object-level cognitions and meta-level cognitions (see Figure 2). The object-level cognitions are typical cognitive processes, such as encoding, imaging, retrieving, and so on. The meta-level cognitions, such as feelings of knowing or judgments of learning, are cognitions specifically directed toward object-level processes but are separable from the cognitions. Nelson argued that monitoring is the flow of information from the object-level to the meta-level and that control is the flow of information from the meta-level to the object-level. In this feedback system, the meta-level can access what the object level's actions are via monitoring and then change and adjust them (control) (see Figure 2).

TOTs play the role of monitoring by informing the rememberers when an item may be retrievable. Functionally, TOTs may alert the rememberers that more time may be necessary to retrieve an item and not to terminate the search (e.g., Ryan et al., 1982). To the extent that one heeds the TOT and continues to attempt to retrieve an item, one is controlling one's retrieval behavior. Thus, TOTs provide the rememberers with useful information that they may then use to control mnemonic behavior.

The critical assumption of the metacognitive model is that monitoring and control are not perfect. Indeed, Nelson (1996) wrote that "the one new twist is to relax the assumption, traditionally made by philosophers, that introspection is infallible" (p. 106). Nelson claims that monitoring is an "imperfect measuring devise of [one's] own cognitions" (p. 106). Nelson's claim is that metacognition allows one to introspect on one's own cognition. Introspection, however, is not always valid (thus distinguishing it from 19th century axioms concerning introspection). One task of the researcher is to determine what kinds of metacognition are accurate predictors of performance.

For the most part, TOTs are valid indices of later memory. Like other forms of metacognition, however, they are not always valid introspective tools. Illusory negative TOTs and TOTs for incorrect items demonstrate the fal-
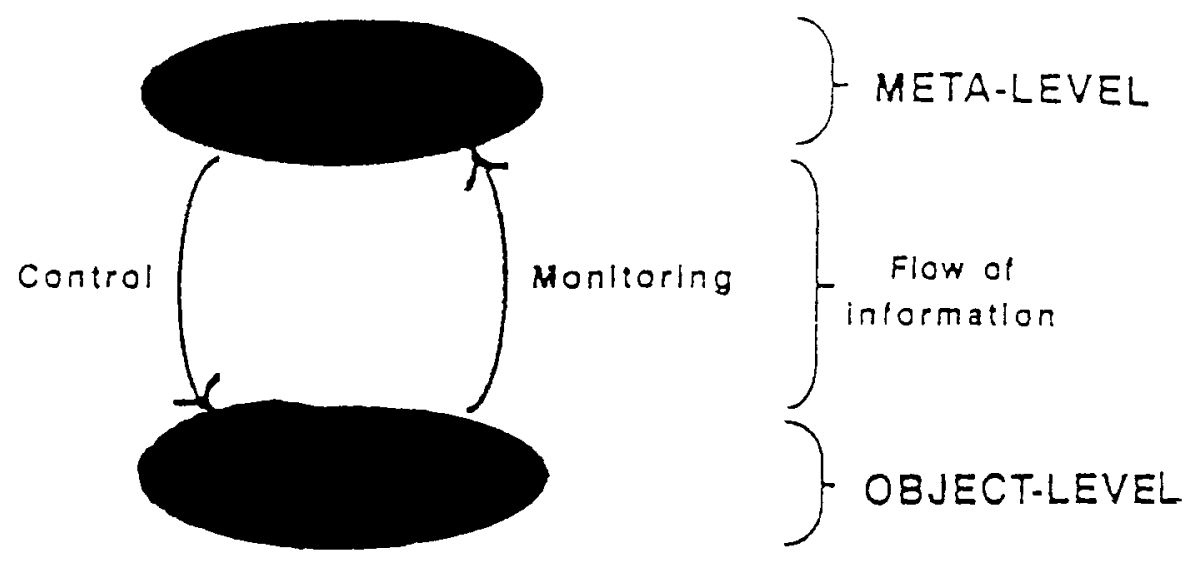

Figure 2. Nelson and Narens's model. From “Why Investigate Metacognition?" by T. O. Nelson and L. Narens, 1994, in J. Metcalfe and A. P. Shimamura (Eds.), Metacognition: Knowing About Knowing (p. 11). Copyright 1994 by MIT Press. Reprinted with permission. 
libility of TOTs in measuring memory performance. Moreover, resolution of objective TOTs is not perfect. As a consequence, researchers must use care when using TOTs to study retrieval processes. Indeed, TOTs, like metacognition in general, offer us a "lens" that brings phenomenology into focus, as opposed to a "window" on the nature of retrieval.

\section{CONCLUSIONS AND GOALS FOR THE FUTURE}

There are four important claims in this article. First, TOTs and word retrieval are experimentally dissociable and may partially arise via different mechanisms. Thus, caution should be used when using TOTs to study the retrieval process. Second, the study of TOTs provides important empirical advantages for the investigation of phenomenology in general because TOTs are easily induced in the laboratory, and laboratory TOTs resemble naturalistic ones. Furthermore, a sizable database concerning TOTs already exists. TOTs appear to be a universal phenomenological experience, since a commonlanguage term exists for it in many languages. Third, although many TOTs may arise from direct-access mechanisms, some TOTs also arise from inferential mechanisms. Fourth, many aspects of research refute the doctrine of concordance. Perhaps the most appropriate guiding principle for TOT research is that of the metacognitive approach-namely, that certain meta-level processes exist to monitor and control object-level cognition and behavior.

What are the important directions for future research to take? We still know very little concerning the scientific bases of consciousness, nor do we know very much concerning TOTs. Future research in this area is open to many different directions and perspectives (see A. S. Brown, 1991). In the current view, the most theoretically rich area in TOT research is the nature and cause of the phenomenological experience of the TOT. Current data suggest a complexity of the nature of the TOT experience and the interaction between phenomenology and object-level cognition in general. Metacognition research has shown that it can avoid the pitfalls of introspectionism (Nelson, 1996) and that research into phenomenological experience is again "fair game."

\section{REFERENCES}

ANDERSON, M. C., \& NeELy, J. H. (1996). Interference and inhibition in memory retrieval. In E. L. Bjork \& R. A. Bjork (Eds.), Memory (pp. 237-417). San Diego: Academic Press

Astell, A. J., \& HARLEY, T. A. (1996). Tip-of-the-tongue states and lexical access in dementia. Brain \& Language, 54, 196-215.

BAK, B. (1987). The tip-of-the-tongue phenomenon: A Polish view. Polish Psychological Bulletin, 18, 21-27

Benjamin, A. S., Bjork, R. A., \& Schwartz, B. L. (1998). The mismeasure of memory: When retrieval fluency is misleading as a metamnemonic index. Journal of Experimental Psychology: General, 127. 55-68.

BJORK, R. A. (1994). Memory and metamemory considerations in the training of human beings. In J. Metcalfe \& A. P. Shimamura (Eds.),
Metacognition: Knowing about knowing (pp. 185-205). Cambridge, MA: MIT Press.

BJORK, R. A., \& BJork, E. L. (1992). A new theory of disuse and an old theory of stimulation fluctuation. In A. F. Healy, S. M. Kosslyn, \& R. M. Shiffrin (Eds.), From learning processes to cognitive processes: Essays in honor of William K. Estes (Vol. 2, pp. 35-67). Hillsdale, NJ: Erlbaum

Brown, A. S. (1991). A review of the tip-of-the-tongue experience. Psychological Bulletin, 109, 204-223.

Brown, A. S., \& Nix, L. A. (1996). Age-related changes in the tip-ofthe-tongue experience. American Journal of Psychology, 109, 79-91.

Brown, R., \& MCNEILL, D. (1966). The "tip of the tongue" phenomenon. Journal of Verbal Learning \& Behavior, 5, 325-337.

Bruce, C., \& Howard, D. (1988). Why don't Broca's aphasics cue themselves? An investigation of phonemic cueing and tip of the tongue information. Neuropsychologia, 26, 253-264.

Burke, D. M., MacKay, D. G., Worthley, J. S., \& Wade, E. (1991). On the tip of the tongue: What causes word finding failures in young and older adults? Journal of Memory \& Language, 30, 542-579.

ConNor, L. T., Balota, D. A., \& NeEly, J. H. (1992). On the relation between feeling of knowing and lexical decision: Persistent subthreshold activation or topic familiarity. Journal of Experimental Psychology: Learning, Memory, \& Cognition, 18, 544-554.

ELBERS, L. (1985). A tip-of-the-tongue experience at age two? Journal of Child Language, 12, 353-365.

FINLEY, G. E., \& SHARP, T. (1989). Name retrieval by the elderly in the tip-of-the-tongue paradigm: Demonstrable success in overcoming initial failure. Educational Gerontology, 15, 259-265.

Funnell, M., Metcalfe, J., \& TsapKani, K. (1996). In the mind but not on the tongue: Feeling of knowing in an anomic patient. In L. M. Reder (Ed.), Implicit memory and metacognition (pp. 171-194). Hillsdale, NJ: Erlbaum.

GaRdiner, J. M., \& JAVA, R. I. (1993). Recognising and remembering. In A. F. Collins, S. E. Gathercole, M. A. Conway, \& P. E. Morris (Eds.), Theories of memory (pp. 163-188). Hillsdale, NJ: Erlbaum.

HARLEY, T. A., \& Bown, H. E. (1998). What causes a tip-of-the-tongue state? Evidence for lexical neighbourhood effects in speech production. British Journal of Psychology, 89, 151-174.

IWASAKI, N., VIGliocco, G., \& GarretT, M. F. (in press). Adjectives and adjectival nouns in Japanese: Psychological processes in sentence production. In Japanese/Korean Linguistics (Vol. 8). Stanford, CA: Stanford University Press.

JaCoby, L. L., Kelley, C. M., \& Dywan, J. (1989). Memory attributions. In H. L. Roediger III \& F. I. M. Craik (Eds.), Varieties of memory and consciousness: Essays in honour of Endel Tulving (pp. 391422). Hillsdale, NJ: Erlbaum.

JAMES, W. (1890). The principles of psychology: Vol. 1. New York: Holt. JONES, G. V. (1988). Analyzing memory blocks. In M. M. Gruneberg, P. E. Morris, \& R. N. Sykes (Eds.), Practical aspects of memory: Current research and issues (Vol. 1, pp. 215-220). New York: Wiley.

JONES, G. V. (1989). Back to Woodworth: Role of interlopers in the tipof-the-tongue phenomenon. Memory \& Cognition, 17, 69-76.

JoNes, G. V., \& LANGFoRD, S. (1987). Phonological blocking in the tip of the tongue state. Cognition, 26, 115-122.

Kohn, S. E., Wingfield, A., Menn, L., Goodglass, H., Berko GleaSON, J., \& HYDE, M. (1987). Lexical retrieval: The tip-of-the-tongue phenomenon. Applied Psycholinguistics, 8, 245-266.

KorIaT, A. (1993). How do we know that we know? The accessibility account of the feeling of knowing. Psychological Review, 100, 609-639.

Koriat, A. (1995). Dissociating knowing and the feeling of knowing: Further evidence for the accessibility model. Journal of Experimental Psychology: General, 124, 311-333.

KORIAT, A. (1997). Monitoring one's own knowledge during study: A cue-utilization approach to judgments of learning. Journal of Experimental Psychology: General, 126, 349-370.

KoRIAT, A., \& Lieblich, I. (1974). What does a person in a "TOT" state know that a person in a "don't know" state doesn't know. Memory \& Cognition, 2, 647-655.

KORIAT, A., \& LiEblich, I, (1977). A study of memory pointers. Acta Psychologica, 41, 151-164.

KozLOWSKI, L. T. (1977). Effects of distorted auditory and of rhyming 
cues on retrieval of tip-of-the-tongue words by poets and nonpoets. Memory \& Cognition, 5, 477-481.

Matison, R., Mayeux. R., Rosen, J., \& Fahn, S. (1982). "Tip-of-thetongue" phenomenon in Parkinson disease. Neurology, 32, 567-570.

MAYLOR, E. A. (1990). Recognizing and naming faces: Aging, memory retrieval, and the tip of the tongue state. Journal of Gerontology, 45, 215-226.

METCALFE, J. (1993). Novelty monitoring, metacognition, and control in a composite holographic associative recall model: Interpretations for Korsakoff amnesia. Psychological Review, 100, 3-22.

MetCalfe, J., Schwartz, B. L., \& Joaquim, S. G. (1993). The cue familiarity heuristic in metacognition. Journal of Experimental Psychology: Learning, Memory, \& Cognition, 19, 851-861.

MeYer, A. S., \& BoCK, K. (1992). The tip-of-the-tongue phenomenon Blocking or partial activation? Memory \& Cognition, 20, 715-726.

Miozzo, M., \& Caramazza, A. (1997). Retrieval of lexical-syntactic features in tip-of-the-tongue states. Journal of Experimental Psychology: Learning, Memory, \& Cognition, 23, 1410-1423.

MuraKaMI, Y. (1980). On the memory unit within kana-letter and kanjiletter words in the tip of the tongue phenomenon. Japanese Journal of Psychology, 51, 41-44.

NELSON, T. O. (1984). A comparison of current measures of the accuracy of feeling-of-knowing predictions. Psychological Bulletin, 95, 109-133.

Nelson, T. O. (1996). Consciousness and metacognition. American Psychologist, 51, 102-116.

Nelson, T. O., Gerler, D., \& Narens, L. (1984). Accuracy of feeling of knowing judgments for predicting perceptual identification and relearning. Journal of Experimental Psychology: General, 113, 282-300

Nelson, T. O., \& Narens, L. (1990). Metamemory: A theoretical framework and new findings. In G. H. Bower (Ed.), The psychology of learning and motivation (Vol. 26, pp. 125-141). San Diego: Academic Press.

Nelson, T. O., \& Narens, L. (1994). Why investigate metacognition? In J. Metcalfe \& A. P. Shimamura (Eds.), Metacognition: Knowing about Knowing (pp. 1-25). Cambridge, MA: MIT Press

Perfect, T. J., \& Hanley, J. R. (1992). The tip-of-the-tongue phenomenon: Do experimenter-presented interlopers have any effect? Cognition, 45, 55-75.

RAJARAM, S. (1993). Remembering and knowing: Two means of access to the personal past. Memory \& Cognition, 21, 89-102.

Rajaram, S., \& Roediger, H. L., III (1997). Remembering and knowing as states of consciousness during retrieval. In J. D. Cohen \& J. W. Schooler (Eds.), Scientific approaches to consciousness (pp. 213240). Hillsdale, NJ: Erlbaum.

Rastle, K. G., \& Burke, D. M. (1996). Priming the tip of the tongue: Effects of prior processing on word retrieval in young and older adults. Journal of Memory \& Language, 35, 586-605.

READ, J. D., \& BRUCE, D. (1982). Longitudinal tracking of difficult memory retrievals. Cognitive Psychology, 14, 280-300.

Reason, J. T., \& LUCUS, D. (1984). Using cognitive diaries to investigate naturally occurring memory blocks. In J. Harris \& P. E. Morris (Eds.), Everyday memory, actions, and absent mindedness (pp. 53 70). London: Academic Press.

REDER, L. M. (1987). Selection strategies in question answering. Cognitive Psychology, 19, 90-138.

Reder, L. M., \& RitTer, F. E. (1992). What determines initial feeling of knowing? Familiarity with question terms, not with the answer. Journal of Experimental Psychology: Learning, Memory, \& Cognition, 18, 435-451.

RoEDiger, H. L., III (1996). Memory illusions. Journal of Memory \& Language, 35, 76-100.

RUBIN, D.C. (1975). Within word structure in the tip-of-the-tongue phenomenon. Journal of Verbal Learning \& Verbal Behavior, 14, 392-397.

Ryan, M. P., Petty, C. R., \& Wenzlaff, R. M. (1982). Motivated remembering efforts during tip-of-the-tongue states. Acta Psychologica, 51, 137-147.

SCHWARTZ, B. L. (1994). Sources of information in metamemory: Judg- ments of learning and feelings of knowing. Psychonomic Bulletin \& Review, 1, 357-375.

Schwartz, B. L. (1998). Illusory tip-of-the-tongue states. Memory, 6, $623-642$.

SChWARTZ, B. L., \& MeTCALFE, J. (1992). Cue familiarity but not target retrievability enhances feeling-of-knowing judgments. Journal of Experimental Psychology: Learning, Memory, \& Cognition, 18, 1074-1083.

Schwartz, B. L., \& Metcalfe, J. (1994). Methodological problems and pitfalls in the study of human metacognition. In J. Metcalfe \& A. P. Shimamura (Eds.), Metacognition: Knowing about knowing (pp. 93-114). Cambridge, MA: MIT Press.

Schwartz, B. L., \& SMITH, S. M. (1997). The retrieval of related information influences tip-of-the-tongue states. Journal of Memory \& Language, 36, 68-86.

Schwartz, B. L., Travis, D. M., Castro, A. M., \& Smith, S. M. (in press). The phenomenology of real and illusory tip-of-the-tongue states. Memory \& Cognition.

SмIтH, S. M. (1994). Frustrated feelings of imminent recall: On the tipof-the tongue. In J. Metcalfe \& A. P. Shimamura (Eds.), Metacognition: Knowing about knowing (pp. 27-46). Cambridge, MA: MIT Press.

Smith, S. M., Balfour, S. P., \& Brown, J. M. (1994). Effects of practice on tip-of-the-tongue states. Memory, 2, 31-49.

Tulving, E. (1983). Elements of episodic memory. Oxford: Oxford University Press.

Tulving, E. (1989). Memory: Performance, knowledge, and experience. European Journal of Cognitive Psychology, 1, 3-26.

Tulving, E., \& Pearlstone, Z. (1966). Availability versus accessibility of information in memory for words. Journal of Verbal Learning \& Verbal Behavior, 5, 381-391.

Vigliocco, G., Antonini, T., \& Garrett, M. F. (1997). Grammatical gender is on the tip of Italian tongues. Psychological Science, $\mathbf{8}$, 314-317.

Vigliocco, G., Vinson, D. P., Martin, R. C., \& Garrett, M. F. (1999). Is "count" and "mass" information available when the noun is not? An investigation of tip of the tongue states in anomia. Journal of Memory \& Language, 40, 534-558.

WeLlman, H. M. (1977). Tip of the tongue and feeling of knowing experiences: A developmental study of memory monitoring. Child Development, 48, 13-21.

Widner, R. L., Smith, S. M., \& Graziano, W. G. (1996). The effects of demand characteristics on the reporting of tip-of-the-tongue states and feeling-of-knowing states. American Journal of Psychology, 109. 525-538,

YANIV, I., \& MEYER, D. E. (1987). Activation and metacognition of inaccessible stored information: Potential bases for incubation effects in problem solving. Journal of Experimental Psychology: Learning, Memory, \& Cognition, 13, 187-205.

\section{NOTES}

1. Throughout this paper, the terms accessibility and availability are defined in the sense intended by Tulving and Pearlstone (1966; also see Bjork \& Bjork, 1992). Availability refers to the sum total of information in memory. Accessibility refers to that which is currently retrievable.

2. Full copies of transliterations can be made available by e-mailing the author.

3. This hypothesis is potentially problematic based on the following logic. The conditions vary with respect to recall in the initial phase, thus creating different pools of unrecalled targets on which TOTs may be made. The condition with the highest initial recall $(\mathrm{A}-\mathrm{B} \mathrm{A}-\mathrm{B})$ creates the smallest pool, presumably with the least variance and potentially the most difficult now. Nonetheless, empirically, Metcalfe et al. (1993) observed significantly higher recognition (Experiments $1-3$ ) and secondchance recall (Experiment 4 ) in the A-B A-B condition. The hypothesis is justified by this empirical finding. Furthermore, the $A-B$ A-D condition resulted in more TOTs than the $\mathrm{A}-\mathrm{B} \mathrm{C}-\mathrm{D}$ condition. 
APPENDIX A

Survey of Spoken Languages That Use and Do Not Use the "Tongue" Metaphor

Use "Tongue" Metaphor Do Not Use "Tongue" Metaphor Indo-European Languages

Afrikaans
Armenian
Bulgarian
Czech
Danish
Dutch
English
Farsi
Flemish
French
German
Gujarati
Haitian Creole
Hindi
Irish
Italian
Marathi
Norwegian
Polish
Portuguese
Russian
Serbo-Croatian
Slovak
Spanish
Swedish
Urdu
Welsh
Yiddish

Arabic

Chamarro

Cheyenne

Chinese (Cantonese)

Chinese (Mandarin)

Estonian

Finnish

Hausa

Hebrew

Hungarian

Ibo

Japanese

Jaru

Korean

Tamil

Turkish

Vietnamese

\section{APPENDIX B}

Translations of Expressions

Using the "Tongue" Metaphor

"On the Tongue"

Cheyenne

Jaru

Marathi

Norwegian

Slovak

Swedish

"On Tip/Point/Head of the Tongue"

Afrikaans

Arabic

Armenian

Bulgarian

Chamarro

Czech

Danish

Dutch

English

Estonian

Farsi

Finnish

Flemish

French

German

Gujarati

Haitian Creole

Hebrew

Hungarian

Italian

Polish

Portuguese

Russian

Spanish

Tamil

Turkish

Urdu

Vietnamese

Yiddish

"On the Top of the Tongue"

Irish

Serbian

"On the Front of the Tongue"

Welsh

"Sparkling at the End of the Tongue" Korean (1)

"In the Mouth and Throat"

Cantonese Chinese

Mandarin Chinese

Hausa

Hindi

Ibo

Japanese

Korean (2) 